\title{
Integrated Learning: Need of the Hour in Medical Education
}

\author{
Arunabha Dasgupta
}

\begin{abstract}
With the introduction of competency-based medical education for undergraduate medical education by the Medical Council of India in our country, the need for reorientation of medical education as per societal needs requires a strengthening link with new reforms in the educational system of which integrated teaching-learning methods are of paramount importance. There is a shift from traditional didactic lectures to interactive discussions, group discussions, and integrated learning sessions. With shedding of too much of information overload from basic science subjects, proposals and efforts are there to incorporate basic science in the context of clinical orientation and teach them in systemwise fashion not in discipline-wise way as in the traditional teaching system it was followed. Hence, the new teaching system where teaching will be system-wise and for one system basic science teaching will be followed by clinical teaching along with clinical exposure at wards is the basic essence of integrated learning. The literature says teaching in this way helps students to understand, retain, and build concepts more effectively than the traditional system. Problem-based learning that enhances integrated learning methods provides relevance to the subjects studied. The need of the hour is a socially accountable medical education in India in alignment with global needs also. So, changes are inevitable. Faculty reorientation as per needs of new education system forms the backbone for successful launching of the program countrywise along with gaining of student's trust. Implementation of the integrated teaching-learning concept is a challenge as it needs extreme cooperation from college administration, medical education unit, college routine committee, individual departments, and individual teachers. There are different models of integrated teaching methods and each one of them is unique. To implement them, there are multiple strategies and for success of running the process smoothly the college administration needs to create environments. Assessment of students too needs certain modifications as the aim of the assessment needs to get aligned with launching goals. The aim of such effort is to create an Indian medical graduate competent in possessing requisite knowledge, exercising requisite skills, having values and attitudes as desired, and act with responsiveness and accountability. They will act with confidence in discharging their duties as the physician of first contact of the community and simultaneously will be globally relevant.
\end{abstract}

Keywords: Integrated learning and teaching, Medical education, Strategies and models of integration.

Bengal Physician Journal (2019): 10.5005/jp-journals-10070-6127

\section{INTRODUCTION}

The word "integration" in the teaching-learning process of medical education means coordination in the teaching process, where subject matters frequently taught in separate academic courses are unified together with an aim of bridging knowledge of students and to build up a meaningful association and understanding. This education process is organized in a way that it cut across subject matter lines and brings together the various aspects of the curriculum to focus upon broad areas of study. ${ }^{1}$ The need for integrated teaching in medical education in India is based on the fact that we are now heading toward the concept of competency-based medical education and this movement is moving away from memorizing and recitation of isolated facts, which is to take care of only the cognitive domain of students. This movement is in building up of a more meaningful concept by students about the scientific literature they are studying and also in creating bridges between various concepts so that a development of a competency occurs with proper linking and understanding.

The learning becomes a holistic experience and at the end of learning process the student develops a comprehensive idea of the theory and practical, which has been taught., 23

Thus, the integrated teaching-learning process can be defined as the art of teaching design that integrates a rich set of teaching, learning, and technical components all together to ensure harmonious functioning of the educational system for more effective learning by students.
Department of General Medicine, Agartala Government Medical College, Agartala, Tripura, India

Corresponding Author: Arunabha Dasgupta, Department of General Medicine, Agartala Government Medical College, Agartala, Tripura, India, Phone: +91 9862007929, e-mail: drarunabhadasgupta@gmail. com

How to cite this article: Dasgupta A. Integrated Learning: Need of the Hour in Medical Education. Bengal Physician Journal 2019;6(3): 62-66.

Source of support: Nil

Conflict of interest: None

The integrated teaching curriculum aims to provide students a better understanding along with improved learning opportunity. It will facilitate the development of knowledge, which will be relevant and meaningful to clinical practice. It will be amenable to alternation if needed and updating. This is contributing to the concept of lifelong learner of a medico. ${ }^{4,5}$

\section{Significance of Integrated Teaching in Medical Curriculum}

Dayna Laur, an educationist, states about the significance of such teaching-learning method and she says,

"Integrated studies aim to create a connectedness between disciplines that otherwise might seem unrelated to many students.

o The Author(s). 2019 Open Access This article is distributed under the terms of the Creative Commons Attribution 4.0 International License (https://creativecommons. org/licenses/by-nc/4.0/), which permits unrestricted use, distribution, and non-commercial reproduction in any medium, provided you give appropriate credit to the original author(s) and the source, provide a link to the Creative Commons license, and indicate if changes were made. The Creative Commons Public Domain Dedication waiver (http://creativecommons.org/publicdomain/zero/1.0/) applies to the data made available in this article, unless otherwise stated. 
Deliberately searching ways in which you can mingle standards and content is imperative if you want to create truly authentic experiences because, in the world outside the classroom, content is not stand alone." ${ }^{\prime 6}$

In medical education, subjects are learnt by attending theory classes, practical, clinical exposure, and tutorials. All are taught in isolation, subject-wise, and no attempt was made to synchronize them. It is believed that students will recapitulate and remember the past academic subjects and will bridge the new topics by themselves in building up concepts, which in reality does not happen. When clinical subjects are taught, little attempt is being made in bringing the basic science subjects, though the former is viewed as the skillful application of the latter. So very few students can comprehend and the aim of development of the desired competency regarding any subject is not achieved. ${ }^{7,8}$

This model now termed as the traditional model allows deeper understanding of the basic science disciplines but at the expense of relevant clinical science whose application needs practical merit. Hence, to make education more useful to students, it is imperative to shift teaching learning methods from subject-wise to systemwise and these methods of teaching will be successful only by the best possible integration of basic science disciplines with clinical disciplines. ${ }^{9}$

So, the integrated teaching-learning method is a process where students can bring together concepts and methods from two or more disciplines in order to explain a phenomenon or solve a problem or create a new project. ${ }^{10}$

\section{Types of Integrated Teaching}

The integrated teaching module is divided into two types:

- Content types of integration

- Pedagogical types of integration

The content type of integration is divided into two types:

- Subject integration

- Domain integration

The pedagogical type is also further subdivided in two types:

- Method integration

- Cognitive integration

Subject integration is of three types:

- Horizontal

- Vertical

- Both

- Horizontal integration is the process of learning within the structure where individual departments contribute to learning in a holistic way. By this method, links are made about a topic by the contributing departments and learning is enriched by connections. Horizontal integration thus brings together a topic and subjects, which were being taught separately by different departments. It is the integration of topics in a same semester by the departments of that semester.

- Vertical integration is the process of teaching by integration from both basic science subjects and clinical subjects where the traditional boundary of pre-para and clinical divide is wiped off. Thus, the basic science subjects are incorporated inside the clinical environment and it is represented in the context of clinical and professional practice. These learning methods have been found to be more relevant and meaningful when taught along with clinical postings at wards.

- Spiral or both the combination of horizontal and vertical is another innovative process of teaching and is a continuous process of transition as a student progresses from normal to abnormal with focus given on cognitive, skill, and attitude level of learning.

Integration in medical education thus breaks the boundaries between different departments and results in increased connectivity between different disciplines because of dissolution of barriers. Thereby, enhancing the student's retention of concepts improves skills and helps to imbibe ethics and attitudes. $^{11,12}$

\section{Various Settings and Environments for Effective Functioning of Integrated TEACHING}

\section{Learner-centered Environment}

This is a platform created for the students aiming to provide careful attention in building up of knowledge, skills, and attitudes by the students. The learners need to develop belief in the educational system. The concept of the term "diagnostic teaching" also fits into this where the students tend to discover with rational thinking what is there in the problem, clears misconceptions by discussions, bridge with old lessons taught, and readjust ideas.

Teachers involved will be responsible to act as a facilitator in building up of conceptions and aid in picking up of technical skills.

\section{Knowledge-centered Environment}

The knowledge-centered environment focuses on information and enables students to understand the activities of various disciplines. The knowledge-centered environment intersects with learnercentered environment to provide an atmosphere for students where attitude building and skill acquisitions happen.

\section{Assessment-centered Environment}

In addition to these two, the environment should also be assessment-centered; the key approaches are the opportunities to have feedback from student, to have revisions, and what is to be assessed must be congruent with learning goals. Assessment should be done along the components of competency gain and should include not only student's performance in terms of cognitive gains but also attitude building and acquisition of skills.

\section{Community-centered Environment}

The learning cannot be completed if the environments are not community-centered. Especially important are the norms for people learning and they allow learning from the community's requirements. ${ }^{13}$

\section{Models of Integrated Teaching}

There are four models of integrated teaching as described by Yin Cheong Cheng (2007):

- Total integration

- Content integration and pedagogy separation

- Content separation and pedagogy integration

- Total separation 
Total separation is the traditional model of teaching, which is fragmented in teaching methods; so, there is lowest complexity.

The desired model is the total integration favoring integration both in content and pedagogy; so, there are complexities in learning methods. $^{14}$

Fogarty in 1991 described three different models of integrated teaching and within these three basic forms there are 10 methodologies.

- Integration within a single discipline

- Fragmented model: Separates topics and courses into distinct disciplines

- Connected model: Connects subjects and topics within same discipline like integrating technical skills with knowledge gain

- Nested model: Creating combinations within the same disciplines

\section{- Integration across disciplines}

- Sequenced model: Topics are taught separately but sequenced while teaching to have a framework to gather concept. Teachers arrange units accordingly so that sequencing is done and students find easier to gain concepts.

- Shared model: This model brings two disciplines come together in delivering one concept. Two disciplines need to plan their teaching so that class can be taken together about same topic.

- Webbed model: In this model, integration is being done based on a theme.

- Threaded model: In this model, intradepartmental integration is done on thinking skill expansion and there is amalgam of knowledge, technical skills, graphic designs, and technology. It's said that it is an integration in synthesis level.

- Integrated model: This model blends different disciplines and overlaps individual disciplines concepts and skills. It is a shared methodology. Contributions of teachers are much needed as it is their effort to help in common things to emerge.

- Integration across learners

- Immersed model: Integration occurs within learners without outside intervention.

- Network model: It is a brain storming method for learners and is totally student-centered. Students direct the integration process. Learners know their topic and self-direct the integration process and can ask for necessary resources. ${ }^{15}$

Apart from these models, there is another model suggested by Pakistan termed as ADIL: assessment-driven integrated learning model. $^{16}$

\section{Challenges in Implementation of INTEGRATED TEACHING}

The faculty members of the medical profession are masters in their own field but what they might lack is the art of teaching or pedagogy. Now there are faculty development programs being conducted by the college medical education unit (MEU); but until recently they were unaware of the fact that research methodologies are available for teaching learning methods even for medical education. New teaching methods in medical education are in the horizon and they all foster active learning and integrated teaching is one such method like competency-based medical education (CBME) or problem-based learning. ${ }^{17}$

Teachers are well adapted with the traditional form of didactic lectures; but the recent concept suggests a reduction in this one-way lectures with promotion in short group discussion. Reluctance from the teachers in giving away with what they are acquainted with forms a major hindrance in implementation.

It will need more time and dedication from the teachers along with motivational orientation programs and will also demand an increase in number of faculty for smooth functioning. ${ }^{18,19}$

There is a need to simplify basic sciences and to omit unnecessary details that increase the information burden and to justify basic sciences with clinical orientation.

Reforms need to be aligning with the college and university goals, and engagement with all stakeholders in the process will lead to a successful implementation.

Implementation of a successful integration program will need infrastructure investment, and hence a cooperative hand from administration will help in fruitful actions.

Once implemented, one of the major challenges that will be faced and will require a dilution is improper preparation. It will degenerate the concept of integrated teaching and the end result will be multiple boring didactic lectures.

Students' readiness too is an important challenge and they need to trust the system and being the most important stakeholder the effort of implementation needs to be learner-centered. Accordingly, the assessment methods will require modifications and needs to be aligned with implementation goals. ${ }^{20}$

\section{Difference with the Traditional System OF LEARNING}

Studies comparing the traditional system with integrated learning methods have been done. In one such study done by Basu et al. from SSKM Hospital Kolkata showed statistically significant results in assessment of students taught by integrated learning (IL) methods than the traditional method. Students trained in IL methods made accurate diagnosis than students trained by the traditional method. Similar results are also documented by other studies done across India. It has been shown by such studies that students fare better when concepts are created by teaching in integrated curriculum.

The studies documented that students felt the positive attitudes of IL methods and recognized the fact that integration of basic sciences with clinical classes and ward exposure created more interest for learning. It helps in better understanding of subjects along with formulation and retention of concepts. Most importantly, the positive interactive discussion with the faculty members of basic science and clinical subjects in the same platform was more helpful. ${ }^{21,22}$

\section{Strategies Needed for Successful IMPLEMENTATION}

The following strategies enumerated below are to be adopted for a successful implementation of the IL program:

- Need analysis and improving infrastructure: This is a joint venture of college administration and college MEU. An effective infrastructure and prior planning will help in rolling down of a new curriculum like CBME. 
- Uniform policy decision at the national level and will be carried out by all colleges: From 2020, the decision of CBME implementation has been rolled down and in this curriculum IL method is an important aspect.

- Training of faculties: It has been already started at regional centers and individual colleges in apprising the faculties about CBME implementation and the changed procedures of the teaching schedules and methods.

- Identifying topics of integration and allotting time for IL and preparing timetable.

- Assessment of IL and obtaining necessary feedback from students and faculties.

While the programs of IL methods are running, the following strategies are adopted for successful continuation of the program:

- Reducing factual overload and by deleting unnecessary information and highlighting the core content.

- Problem-based learning or PBL:These will be the main strategies of IL teaching methods. A case is allotted to a small group of students at the start of the week and students go for selfdirected learning and explore the case and the case is discussed along with faculties at the end. The teachers do not teach the case but facilitate in gaining learning objectives.

- Service-based learning: More than half of medical graduates become general practitioners; hence, increased use of community-based learning will help to provide students a broader view of health care.

- Assessment influencing learning: Introduction of this novel curriculum must find innovative ways to assess students and evaluate courses. In an assessment-driven course, student rope in learning methods.

- Self-directed learning: Opportunities for self-directed learning are given in the new curriculum and learning will be in small groups of students favoring group discussion and in making a project or solve a problem given.

- System-based approach: Most important aspect of IL method of teaching. A system is selected by the routine committee of college in consultation with the contributing departments and in the given period of time that system is taught, which includes basic science disciplines and clinical disciplines along with ward exposure of patients having ailments of that system. ${ }^{11,23,24}$

\section{InTEgRATION LADDER}

Curriculum integration is a complex topic but an important strategy in medical education with introduction of CBME. R. M. Harden, an educationalist, coined the term "integration ladder" in 2000 for the medical education system, which defines 11 steps of a ladder in between the two extremes of teaching. In one end is the subjectbased teaching termed as "isolation" by him and in the top is the transdisciplinary approach of integrated teaching. There are in between nine steps of integrated teaching approaches. Among them, few important steps are harmonization, nesting, temporal coordination, sharing, multidisciplinary, and interdisciplinary approaches. Each of these methods is clearly defined and has unique existence. As one moves up the integration ladder, there is less emphasis on the role of the disciplines in the curriculum. Instead, an increasing requirement for a central curriculum organizational structure with appropriate resources at its disposal is the demand. Hence, there is a need for greater participation by MEU in curriculum discussions and planning. Along with, communication and joint ventures by teachers from multiple disciplines are required for smooth function. So, faculty development is well recognized for successful implementation for any reforms. ${ }^{25}$

\section{The Future}

Medical students wait a longer time to shoulder clinical responsibility. Shortening the period will be a welcome step. Broadening the learning experience with early clinical exposure and IL methods will prepare a competent young doctor ready to enter specialist training. These new methods are going to produce medical graduates with different understanding and ethical values apt for the society. ${ }^{26}$

\section{Conclusion}

"Integration seeks to deal more with principles and concepts that can be used to explore and understand problems and develop new solutions."

Both CBME and IL offer a deeper understanding of various topics and issues including the interrelationships inherent between the topics with the aim of a high-level performance in the real world. In India, motivated faculties in medical colleges have taken initiatives to develop the field of medical education. Motivated faculty can bring a change in the education system as per guidelines of the Medical Council of India for implementation of CBME. Competency-based medical education has been planned toward the need of the societal health care and also in alignment of global needs. All initiatives including IL methods will help the movement of linking medical education with the healthcare needs of the present world. ${ }^{27}$

\section{ACKNOWLedgments}

The MCI Nodal Center for Faculty Development of Shri Ramachandra Medical College and Research Institute, Chennai, and members of 5th ACME course for the kind help and guidance.

\section{References}

1. Kate MS, Kulkarni UJ, Supe A, et al. Introducing integrated teaching in undergraduate medical curriculum. Int J Pharma Sci Res 2010;1(1): $18-22$.

2. Glennys JP, Bligh J. The changing context of undergraduate medical education. Postgrad Med J 1995;71(837):397-403. DOI: 10.1136/ pgmj.71.837.397.

3. Carol C, Susan D, Wolfsthal, et al. Shifting paradigms: From Flexner to competencies. Acad Med 2002;77(5):361-367.

4. Ronald ME. Assessment in medical education. N Eng J Med 2007;356(4):387-396. DOI: 10.1056/NEJMra054784.

5. Gustava $A Q$, Jhon $V$, Matha $A$, et al. Integrated medical curriculum: advantages and disadvantages. J Med Edu Curric Dev 2016;3:537-540.

6. Laur D, Timothy K. Deepening natural curiosity: the future of PBL design. Soc Inf Tech Teacher Edu Int Con 2019. 2475-2478.

7. Shoemaker BJE. Integrative education: A curriculum for 21 st century. OSSC Bull 1989;33(2):n2.

8. Harden RM. Approaches to curriculum planning. Med Edu 1986;20(5):458-466. DOI: 10.1111/j.1365-2923.1986.tb01193.x.

9. Harden RM, Sowden S, Dunn WR. Educational strategies in curriculum development: the SPICES model. Med Edu 1984;18(4):284-297. DOI: 10.1111/j.1365-2923.1984.tb01024.x.

10. Amudha K, Sunil G. Integrated learning in medical education: Are our students ready? Med Sci Edu 2015;25:549-551. DOI: 10.1007/s40670015-0172-0. 
11. David GB, Krsiti JF. The integrated curriculum in medical education: AMEE Guide no-96. J Med Teacher 2015;37(4):312-322. DOI: 10.3109/0142159X.2014.970998.

12. Samar AS, Soad SA, Nasra NA, et al. A model of horizontal and vertical integration of teaching on a cadaveric heart. Ann Anat 2010;192(6):373-377. DOI: 10.1016/j.aanat.2010.06.005.

13. Steward TJ. Learning environments in medical educations. Med Teacher 2006;28(4):387-389. DOI: 10.1080/01421590600727043.

14. Cheng CY. Multiple models of integrated learning: conception, effectiveness and creativity. Conference on integrated learning: research and classroom practice. HKIEd.14th Dec 2007.

15. Fogarty R. Ten ways to integrate the curriculum: integrating curriculum. Educational leadership 1991. 61-65.

16. Khan JS. Assessment driven integrated learning: assessment directed medical education curriculum. J Ayub Khan Med Coll Abodatabad 2010;22(4):201-206.

17. Rashmi V. The need and recent trends in medical education. J Basic Med Allied Sci 2012;1(2):7-18.

18. Neelam AT, Monica L, Riti JS, et al. Introduction of integrated teaching learning module in second MBBS curriculum. Int J Con Med Res 2016;3(5):1275-1279.

19. Ioannis TT, Chrysanthos S, Konstantinos TT, et al. Contribution of integrated teaching in the improvement of an undergraduate ophthalmology curriculum. Adv Med Edu Pract 2014;5:433-437.
20. Alam SM, Ruksana HM. 12 tips for developing an integrated curriculum. J Med Tech 2011;33(2):99-104.

21. Ravichandran D, Shankar R. The effectiveness of integrated teaching over traditional teaching among 1st year MBBS students: a preliminary study. Med J D.Y. Patil Vid 2013;6(2):139-141.

22. Basu M, Das P, Chowdhury G. Introducing integrated teaching and comparison with traditional teaching in undergraduate medical curriculum: a pilot study. Med J D. Y. Patil Vid 2015;8(4):431-438. DOI: 10.4103/0975-2870.160778.

23. Jogelkar S, Bhuiyan PS, Kishore S. Integrated teaching: our experience. J Postgrad Med 1994;40:231-232.

24. Dandannavar VS. Effect of integrated teaching versus conventional lecturing on MBBS phase I students. Recent Res Sci Technol 2010;2:40-48.

25. Harden RM. The integration ladder: a tool for curricular planning and evaluation. Med Edu 2000;34(7):551-557. DOI: 10.1046/j.13652923.2000.00697.x.

26. Kumari KM, Mysorekar VV, Raja S. Students perception about integrated teaching in an undergraduate medical curriculum. J Clin Diagn Res 2011;5:1256-1259.

27. Jamkar A, Yemul V, Singh G. Integrated teaching programme with student centred case based learning. Med Edu 2006;40(5):466-467. DOI: 10.1111/j.1365-2929.2006.02438.x. 